\title{
Pembuatan Roti Berbahan Dasar Tepung Mocaf "Cooking Mocaf"
}

\author{
Tino Firmansyah*1, Eko Budi Cahyono ${ }^{2}$, Wildan Suharso ${ }^{3}$ \\ 1,2,3 Teknik Informatika/Universitas Muhammadiyah Malang \\ tinofirmansyah25@gmail.com
}

\begin{abstract}
Abstrak
Roti merupakan makanan yang sering dikonsumsi di Indonesia. Bahan dasar dalam pembuatan roti tersebut berupa tepung terigu yang terbuat dari bahan baku dari gandum, sedangkan budidaya gandum di Indonesia belum ada, oleh Karena itu tepung mocaf adalah peluang besar untuk bahan dasar sebagai pengganti gandum tersebut dan di Indonesia sangat lah mudah dalam mebudidayakan singkong tersebut. Melihat kondisi ini maka harus dilakukan pengenalan sistem atau pendekatan kepada masyarakat berupa game edukasi. Game edukasi sendiri merupakan game yang mendidik bagi para penggunanya yang bertujuan membuat permainan tidak jenuh dan tidak membosankan, Dengan harapan game edukasi ini bisa membantu dalam pola pikir masyarakat dalam hal memahami dan mengetahui cara pengolahan roti menggunakan tepung mocaf. Dengan melihat perkembangan ini diharapkan tepung mocaf bisa dijadikan bahan pengganti sebagai bahan dasar pembuatan roti. Dengan melihat peluang ini sehingga bisa membantu masyarakat untuk lebih mengenal tepung mocaf dan bagaimana cara membuat tepung mocaf tersebut menjadi bahan pangan olahan roti dengan cara membuat pemecahan masalah tersebut dengan membuatkan game edukasi sebagai alat bantu untuk mengenalkan tepung mocaf bisa dijadikan bahan baku sebagai pembuatan roti.
\end{abstract}

Kata Kunci: Mocaf, Game, Edukasi, Roti

Bread is a food that is often consumed in Indonesia. The basic ingredients in making the bread are wheat flour made from raw material from wheat, while wheat cultivation in Indonesia does not yet exist, therefore mocaf flour is a great opportunity for basic ingredients as a substitute of wheat and in Indonesia is very easy in cultivating the cassava. Seeing this condition must be done the introduction of the system or approach to the public in the form of educational games. Educational game itself is an educational game for its users that aims to make the game is not saturated and not boring, In the hope that this educational game can help in the mindset of people in terms of understanding and knowing how to process bread using mocafflour. By looking at this development is expected mocaf flour can be used as a substitute as the basic ingredients of bread making. By looking at this opportunity so that it can help people to know more about mocaf flour and how to make mocaf flour into a foodstuff processed bread by making the problem solving by making educational games as a tool to introduce mocaf flour can be used as raw materials for making bread.

Keywords: Bread, Mocaf flour, Game

\section{Pendahuluan}

Tepung Mocaf (Modified Cassava Flour) dalam bahasa indonesia disebut sebagai tepung yang berasal dari singkong, proses pembuatannya melalui proses fermentasi yang melibatkan mikrobia. Dimana dalam proses fermentasi terjadi berbagai macam perubahan kimia, fisik, dan mikrobiologis. Bahan tepung mocaf sendiri bisa memproduksi bahan baku terigu atau beras dengan perbandingan sistem antara $5-75 \%$. Dengan melihat perkembangan ini diharapkan tepung mocaf bisa dijadikan bahan pengganti sebagai bahan dasar pembuatan roti [1]. Singkong merupakan pilihan yang tepat untuk menjawab pemenuhan kebutuhan pengganti bahan baku gandum tersebut. Singkong sendiri sangatlah mudah di tanam di Indonesia dan tidak perlu membutuhkan perawatan yang sulit, Karena singkong bisa dijadikan tepung yakni dikenal dengan sebutan tepung mocaf [2]. 
Roti merupakan makanan yang sering dikonsumsi di Indonesia. Bahan dasar dalam pembuatan roti tersebut berupa tepung terigu yang terbuat dari bahan baku dari gandum, sedangkan budidaya gandum di Indonesia belum ada, oleh Karena itu tepung mocaf adalah peluang besar untuk bahan dasar sebagai pengganti gandum tersebut dan di Indonesia sangat lah mudah dalam mebudidayakan singkong tersebut. Melihat kondisi ini maka harus dilakukan pengenalan sistem atau pendekatan kepada masyarakat berupa game edukasi [3]. Adapun jenisjenis roti yakni roti tawar merupakan roti yang terbuat dari adonan tanpa menggunakan telur dengan sedikit gula atau tidak sama sekali [4], roti manis merupakan makanan yang terbuat dari tepung terigu yang diragikan dengan ragi roti dan dipanggang [5]

Game edukasi sendiri merupakan game yang mendidik bagi para penggunanya yang bertujuan membuat permainan tidak jenuh dan tidak membosankan, Dengan harapan game edukasi ini bisa membantu dalam pola pikir masyarakat dalam hal memahami dan mengetahui cara pengolahan roti menggunakan tepung mocaf [6] Game yang tepat ialah game genre Role Playing Game dikarenakan jenis genre ini berisi unsur-unsur cerita yang kompleks serta seni peran yang membuat user merasa seperti menjadi tokoh yang diperankannya dalam game ini, disini peran yang akan dimainkan berupa peran menjadi koki [7]. Melihat perkembangan teknologi saat ini maka sangat berpeluang untuk melakukan pendekatan karena pada saat ini perangkat yang terbanyak digunakan di Indonesia adalah yang berbasis android[8].

Dengan melihat peluang ini sehingga bisa membantu masyarakat untuk lebih mengenal tepung mocaf dan bagaimana cara membuat tepung mocaf tersebut menjadi bahan pangan olahan roti dengan cara membuat pemecahan masalah tersebut dengan membuatkan game edukasi sebagai alat bantu untuk mengenalkan tepung mocaf bisa dijadikan bahan baku sebagai pembuatan roti. Dalam hal ini juga akan membantu para petani ubi-ubian dalam berusaha yang terdapat pada Desa Tirtoyudo [9]

\section{Metode Penelitian}

\subsection{Metode Pengembangan Sistem}

Tahapan-tahapan penelitian yang dilakukan untuk pembuatan tugas akhir ini menggunakan GDLC (Game Development Life Cycle) sebagai berikut :[10]

a) Studi Pustaka

Studi pustaka dilakukan guna mengumpulkan dan mempelajari teori-teori yang berhubungan dengan pembuatan game platformer $2 \mathrm{~d}$ menggunakan Unity dengan bahasa pemrograman C\# dengan membaca buku yang berkaitan dengan pembuatan aplikasi dan game menggunakan Unity dan mencari artikel dan informasi lainnya dari internet.

b) Initition

Pada tahap ini akan dilakukan pembuatan konsep game yang ingin dibangun, akan seperti apa game itu dibangun. Pada Initiation akan menghasilkan konsep game dan deskripsi sederhana game.

c) Pre-Production

Tahapan sebelum production yaitu tahapan untuk melakukan perancangan dan membuat desain game.

d) Production

Pada tahap ini adalah tahap produksi atau realisasi pembuatan game yang sudah di desain pada tahap Pre-production. Pembuatan asset game seperti core asset, GUI, dan music yang dibutuhkan di dalam game serta integrasi asset dan source code agar menjadi game yang bisa dimainkan.

e) Testing

Pada tahapan ini akan dilakukan pengujian pada game yang sudah dibuat. Pengujian dilakukan oleh internal tim untuk menguji, pada testing akan menghasilkan laporan bug, pada hasil ini nantinya akan memutuskan apakah game sudah siap untuk memasuki beta testing atau mengulangi ke tahap pre-production, metode testing yang digunakan adalah metode Heuristic Evaluation for Playability (HEP) metode yang dilakukan dengan melakukan pengujian secara langsung oleh pengguna dengan menginstal dan memainkannya

f) Beta

Beta adalah pengujian lanjutan setelah testing yang diuji oleh internal tim dan sekarang akan di uji oleh external atau diluar tim, dalam pengujian ini akan menghasilkan laporan bug atau error dan feedback dari user, pada tahap ini pengujian dilakukan dengan kuesioner kepada 30 responden dengan rentan umur 18 tahun sampai 30 tahun, apabila game sudah berjalan

REPOSITOR, Vol. 2, No. 4, April 2020: 455-462 
dengan baik maka dapat lanjut ke tahap berikutnya, tetapi apabila belum maka bisa kembali ke tahap pre-production.

g) Release

Pada tahap ini pembuatan game sudah mencapai tahap akhir dan berarti game sudah siap di publish ke publik. Game sudah resmi diluncurkan serta mengakhiri pembuatan game dan membuat dokumentasi pengembangan.

h) Pembuatan Dokumen Tugas AkhirDilakukan pembuatan dokumen tugas akhir untuk mendokumentasikan penelitian yang sudah dilakukan agar dapat digunakan untuk pengembangan selanjutnya.

\subsection{Perancangan GamePlay}

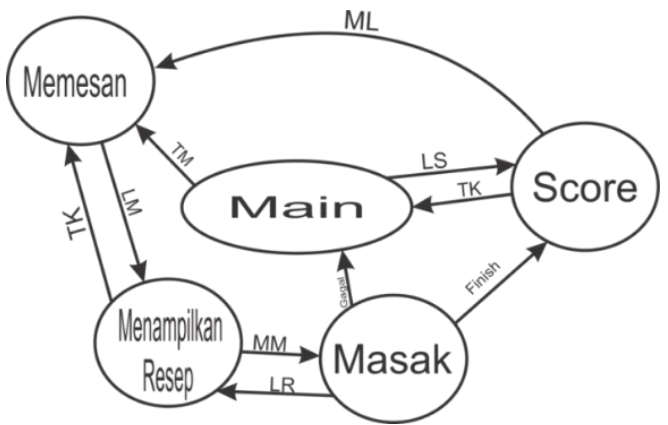

Gambar 1 Finite State Machine Gameplay

Keterangan Gambar 1:

TM : Tekan Tombol Masuk.

LM : Lanjut Memasak.

TK : Tekan Kembali.

MM : Mulai Memasak.

LR : Liat Resep.

LS : Liat Score.

ML : Main Lagi.

Gagal : Pemain gagal dalam proses memasak roti.

Finish : Pemain berhasil menyelesaikan game dan mendapatkan score.

Gambar 1 berikut ini gameplay dari permainan Main adalah pada saat aplikasi sedang berjalan, lalu pemain menekan tombol main, kemudian muncul state pemesan dimana aka ada pelanggan yang memesan roti, pada state ini akan muncul pilihan jenis roti dan akan keluar beserta resep yang sesuai dengan jenis roti yang akan dipilih. Pada state menampilkan resep pemain bisa kembali ke state memesan jika tidak ingin membuat resep yang dipilih, kemudian pemain melakukan memasak, dan pada state memasak pemain akan mendapatkan rintangan berupa waktu, jika berhasil maka score akan didapatkan, jika pemain ingin melanjutkan ke stage selanjutnya maka pemain hanya menekan tombol lanjut otomotis langsung berada pada state memesan.

\subsection{Perancangan Karakter}

Ini adalah rancangan desain karakter yang ada di dalam game "Cooking Mocaf", sebagai berikut: A. Koki (Player)

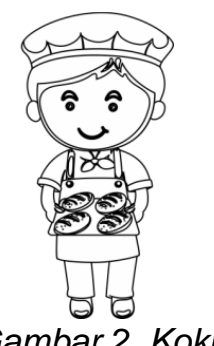


Pada gambar 2 merupakan tampilan karakter koki pada game yang dibuat.

B. Pemesan (Ali, Burhan, dan Jih)

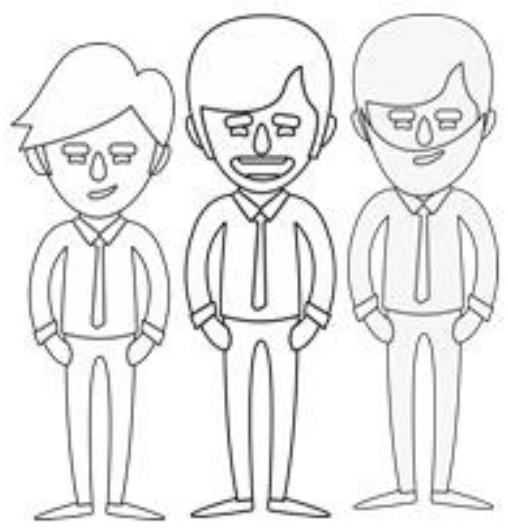

Gambar 3. Ali, Burhan dan Jih

Pada gambar 3 ini merupakan karakter pemesan yang terdapat pada game ini.

\subsection{Rancangan Alur Sistem}
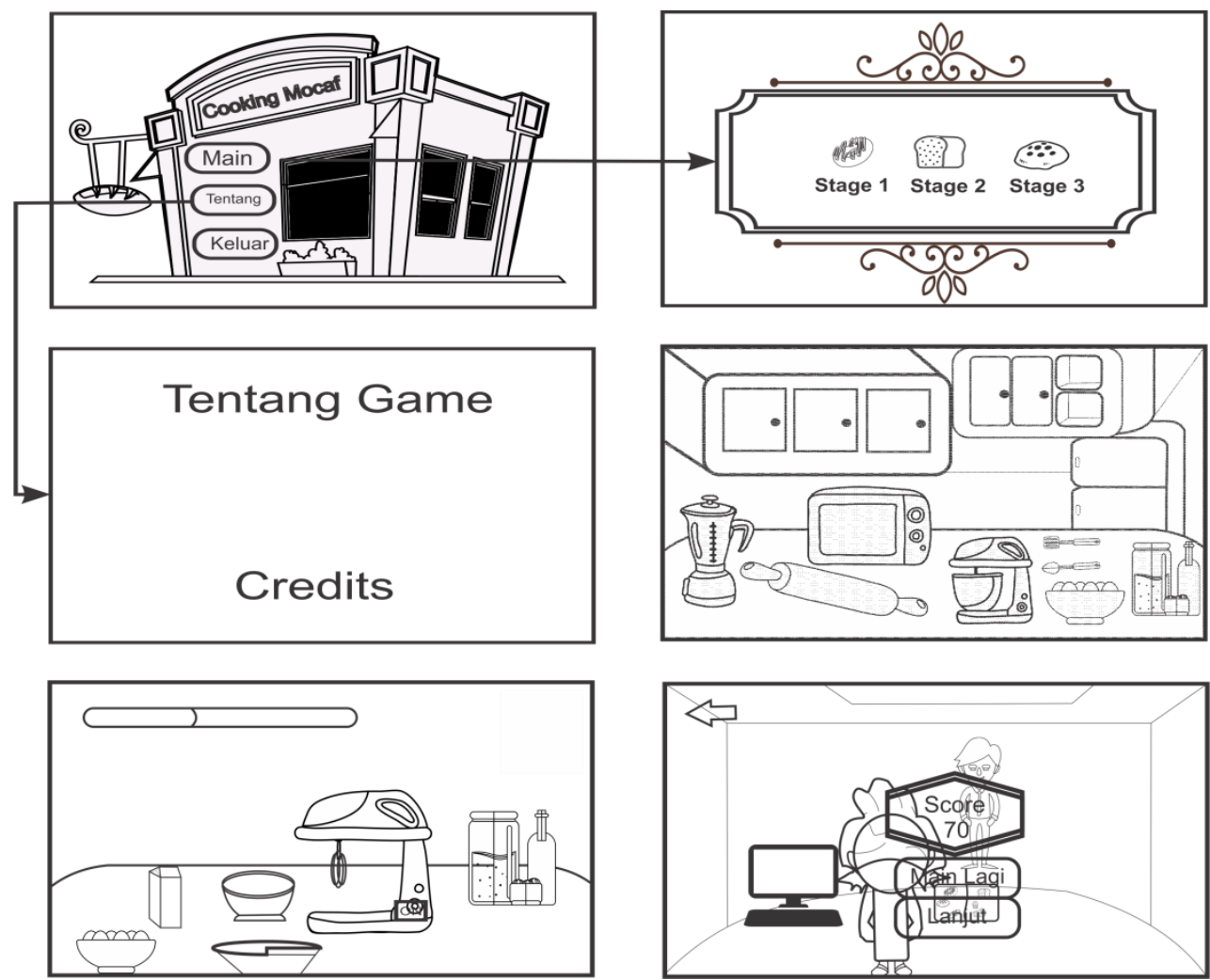

Gambar 4. Rancangan Alur Sistem

Pada Gambar 4 merupakan menu utama dijelaskan bahwa setelah pemain memilih menu main, maka pemain akan menemukan pilihan jenis roti yang akan dibuat, setelah pemain memilih salah satu jenis roti maka pemain diarahkan ke tampilan dapur. Apabila pemain memilih menu tentang maka tampilan kredit akan tampil dimana disini berisi biografi pembuat game secara singkat.

Pada tampilan dapur, pemain akan memilih jenis-jenis alat yang akan digunakan dalam membuat roti, yang sesuai dengan perintah, selanjutnya pemain akan melakukan proses adonan roti.

REPOSITOR, Vol. 2, No. 4, April 2020: 455-462 
Pada tampilan adonan, pemain akan melakukan pencampuran segala macam bahan yang telah diambil,

Selanjutnya akan mucul tampilan score yang diperoleh saat memainkan game, kemudian pemain akan memilih menu main lagi apabila ingin mengulang stage roti yang sudah dimainkan, apabila memilih menu lanjut, maka pemain akan memilih stage dengan resep roti yang berbeda.

\section{Hasil Penelitian dan Pembahasan}

\subsection{Implementasi Karakter}

A. Koki (Player)

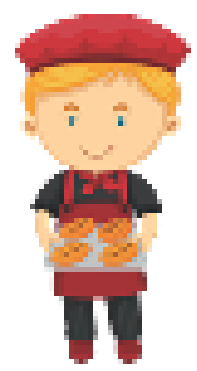

Gambar 5. Implemntasi Karakter Koki ini.

Pada Gambar 5 merupakan hasil dari rancangan karakter koki yang terdapat pada game

B. Pemesan (Ali, Burhan, dan Jih)

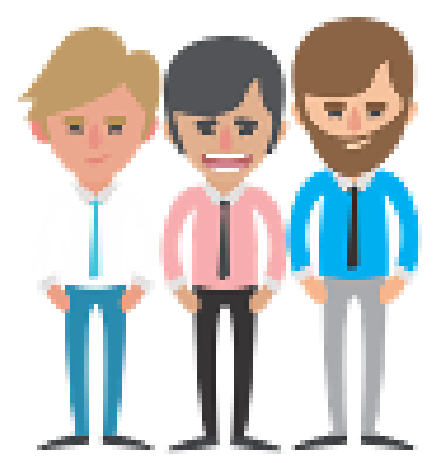

Gambar 6. Implementasi Karakter Pemesan (Ali, Burhan, dan Jih)

Pada Gambar 6 ini merupakan hasil rancangan tampilan karakter pemesan yang terdapat pada game.

\subsection{Implementasi Modul}

A. Implementasi Modul Halaman Utama

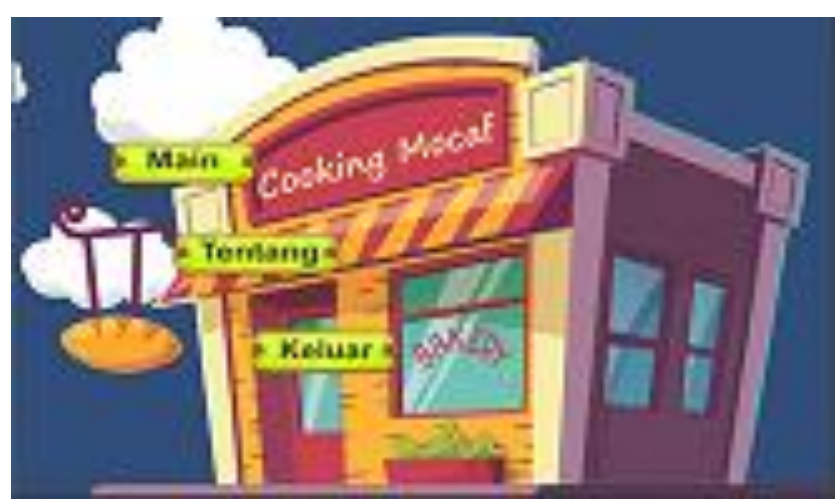

Gambar 7. Menu Utama 
Pada Gambar 7 merupakan menu utama terdiri dari Menu Main, Menu Tentang, Menu Keluar.

B. Implementasi Modul Pemesan

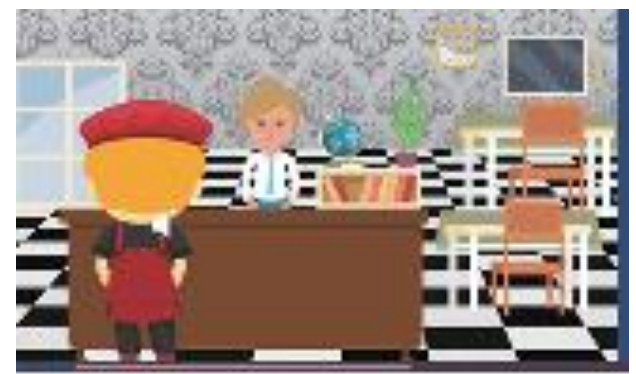

Game 8. Tampilan Pemesan

Pada Gambar 8 Tampilan pada saat pemain memilih menu main pada Gambar 7 maka pemain akan memasuki tampilan pemesan seperti gambar diatas.

C. Implementasi Modul Stage

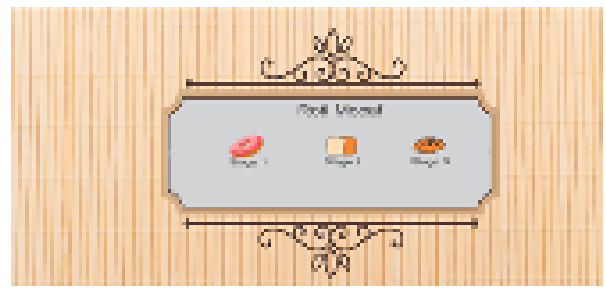

Game 9. Tampilan Stage

Pada Gambar 9 disini pemain bisa memilih 3 pilihan stage yang tersedia dan resep-resep yang berbeda.

D. Implementasi Modul Resep

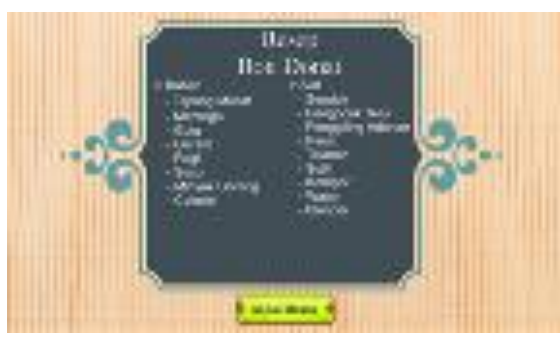

Gambar 10. Pemilihan Stage

Pada Gambar 10 disini pemain akan diberitantangan untuk mengingat resep yang tertera agar pada proses pemilihan alat dan bahan bisa dijalankan.

E. Implementasi Modul Pembuatan Tepung

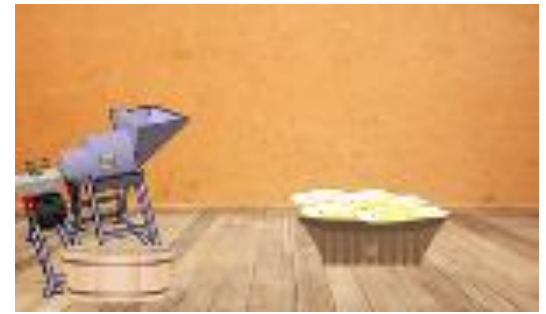

Gambar 11. Proses Pembuatan Tepung

REPOSITOR, Vol. 2, No. 4, April 2020: 455-462 
Pada Gambar 11 disini pemain akan memasukan singkong kedalam mesin, sebelum memasukan kedalam mesin maka pemain harus menekan tombolon yang terdapat pada mesin agar prosesnya dapat berjalan.

F. Implementasi Modul Alat dan Bahan

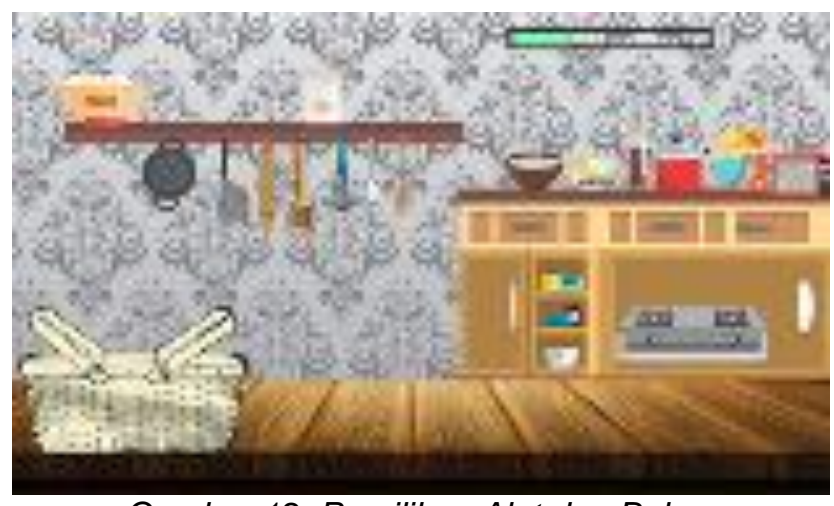

Gambar 12. Pemilihan Alat dan Bahan

Pada Gambar 12 disini pemain akan memilih alat dan bahan sesuai dengan yang terdapat dibuku resep pada scene sebelumnya, smemilih dan memasukan kedalam keranjang, apabila brang yang dipilih salah maka akan mengurangi score pemain dan apabila pemain memilih alat yang benar maka indikator akan berjalan dan apabila indikator penuh artinya pemain sudah memilih barang yang sesuai dengan resep.

G. Implementasi Modul Proses Adonan

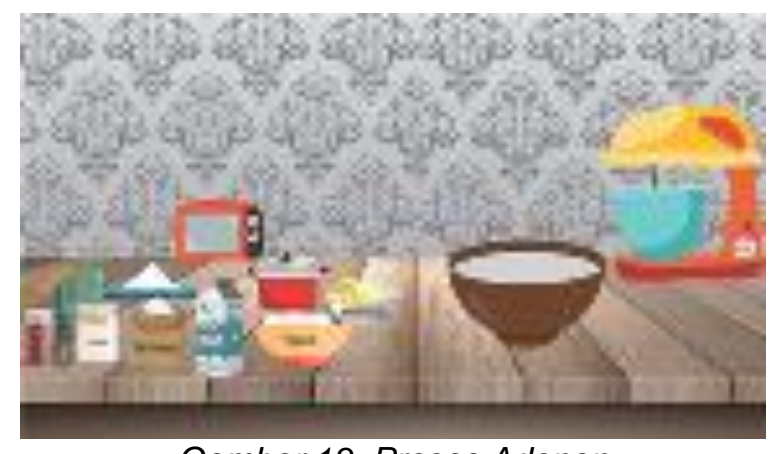

Gambar 13. Proses Adonan

Dari Gambar 13 disini pemain hanya cukup menakan bahan-bahannya saja maka otomatis bahan tersebut akan menjalankan animasi, setelah itu baru pemain bisa menekan tombol on pada blender.

H. Implementasi Modul Proses Akhir

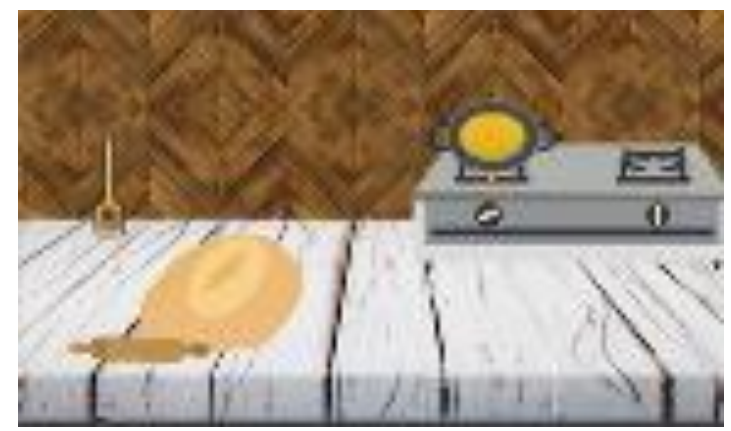

Gambar 14. Proses Akhir

Pembuatan Roti Berbahan Dasar... Tino Firmansyah, Eko Budi Cahyono, Wildan Suharso 
Pada Gambar 14 disini pemain hanya menkan bahan yang tersedia maka otomatis animasi dijalankan, tantangan disini apbila pemain terlalu lama melakukan penggorengan maka roti tersebut akan gosong.

\section{Kesimpulan}

Berdasarkan dari hasil semua pembuatan tugas akhir ini maka dapat disimpulkan bahwa pembuatan game ini sangat membantu untuk memperkenalkan tepung mocaf kepada masyarakat. Untuk proses pengembangan game ini mungkin sebaiknya ditambahkan lagi pemilihan stage yang lebih banyak dan untuk proses memainkannnya lebih diperbaiki lagi proses animasi setiap benda yang disentuh.

\section{Referensi}

[1] S. Sunarsi, M. S. A, S. Wahyuni, and W. Ratnaningsih, "Memanfaatkan Singkong Menjadi Tepung Mocaf untuk Pemberdayaan Masyarakat Sumberejo," Semin. Has. Penelit. dan Pengabdi. Kpd. Masy., no. 1, pp. 306-310, 2011.

[2] P. Tepung and S. Sebagai, "Terigu Untuk Variasi Cake Jurusan Pendidikan Kesejahteraan Keluarga," vol. 5, no. 1, 2016.

[3] A. Arlene and J. R. Witono, "Pembuatan Roti Tawar Dari Tepung Singkong Dan Tepung Kedelai," Simp. Nas. RAPI VIII, pp. 80-84, 2009.

[4] J. Pendidikan, K. Keluarga, F. Teknik, and U. N. Semarang, "Substitusi Tepung Kulit Ari Kedelai Varietas Us . No . 1," no. 1, 2015.

[5] Sudarno. 2015. "Eksperimen Pembuatan Roti Tawar Substitusi Tepung Kulit Ari Kedelai Varietas Us. No.1". Universitas Negeri Semarang

[6] Zainudin, Ahmad "Pengenalan Android". Politeknik Elektronika Negeri Surabaya.

[7] A. D. Wulandari, "Game Edukatif Sejarah Komputer Menggunakan Role Playing Game (RPG) Marker XP Sebagai Media Pembelajaran di SMP Negeri 2 Kalibawang," Game Edukatif Sej. Komput. Menggunakan Role Play. Game Marker XP Sebagai Media Pembelajaran di SMP Negeri 2 Kalibawang, 2012.

[8] D. W. Putra, A. P. Nugroho, and E. W. Puspitarini, "Game Edukasi Berbasis Android Sebagai Media Pembelajaran Untuk Anak Usia Dini," J. TEKNOIF, vol. 1, no. 1, pp. 46-58, 2016.

[9] P. Studi, T. Informatika, F. Teknik, and U. M. Malang, "Pelaku Usaha Berbahan Baku Ubi Kayu," pp. 387-393, 2016.

[10] R. Ramadan and Y. Widyani, "Game development life cycle guidelines," 2013 Int. Conf. Adv. Comput. Sci. Inf. Syst., no. September 2013, pp. 95-100, 2013. 